\title{
Tornar-se um Historiador das Relações Internacionais no
}

\section{Brasil}

\begin{abstract}
Thiago Gehre Galvão ${ }^{1}$
Professor do Instituto de Relações Internacionais - UnB gehre.unb@gmail.com

Como citar este artigo: GALVAO, Thiago Gehre. "Tornar-se um Historiador das Relações Internacionais no Brasil”, Intelligere, Revista de História Intelectual, $\mathrm{n}^{\circ} 10$, pp. 162-177. 2020. Disponível em $<$ http://revistas.usp.br/revistaintelligere $>$. Acesso em dd/mm/aaaa-
\end{abstract}

Resumo: As vivências, intersubjetividades e intertextualidades entre o autor e Amado Luiz Cervo constituem o fio condutor desta narrativa que visa reafirmar ao mesmo tempo a relevância da História para o estudo das Relações Internacionais, o lugar do historiador como internacionalista; bem como o fato de que nos tornamos parte do tecido social, com representatividade, significância e identidade, na medida em que vivemos em um emaranhado complexo de relações emocionais, psicológicas e institucionais. Amado Cervo é o personagem principal desta narrativa que o entende como um tipo ideal que inspira gerações. Ao mesmo tempo, auxilia na tarefa de esquematizar alguns elementos definidores da trajetória e do ofício de historiador de Relações Internacionais, tais como viver o internacional, delinear um mapa de ações, olhar o mundo por lentes críticas, capturar os tempos, preservar as memórias e pensar o futuro.

Palavras-chave: História das Relações Internacionais; História dos conceitos; História das ideias; Relações Internacionais.

\section{Becoming a Historian of International Relations in Brazil}

\footnotetext{
1 Thiago Gehre é coordenador do Programa Estratégico UnB2030: Sustentabilidade e Desenvolvimento Inclusivo. Doutor em Relações Internacionais pela Universidade de Brasília e Professor do Instituto de Relações Internacionais da UnB. Orcid: https://orcid.org/00000001-9951-288X; Lattes: http://lattes.cnpq.br/0445717686469340; E-mail: gehre.unb@gmail.com
} 


\begin{abstract}
Experiences, intersubjectivities and intertextualities between the author and Amado Luiz Cervo constituted a guiding thread in this narrative that aims to reaffirm at the same time the relevance of History for the study of International Relations and the historian's place as an internationalist. Another main objective is to demonstrate the fact that we become part of the social fabric, with representativeness, significance, and identity, only by living in a complex entanglement of emotional, psychological, and institutional relationships. Amado Cervo is the main character of this narrative, an ideal type that inspires generations of intellectuals. From an autobiographical point of view it is possible to shade some light on defining elements of the trajectory and career of the historian of International Relations in Brazil, such as living the international, drawing up a map of actions, looking at the world through critical lenses, capturing times, preserving memories and thinking about the future.
\end{abstract}

Keywords: History of International Relations; History of concepts; History of ideas; International Relations.

Este artigo tem o objetivo de aportar algumas reflexões sobre os desafios de se tornar um Historiador das Relações Internacionais (RI) no Brasil. Trata-se de reflexão sobre como o encontro de gerações suscita forças criativas e de continuidades em um contexto de permanente questionamento da relevância da História para o estudo das Relações Internacionais (GILBERT, 1968). O texto foi desenhado como uma narrativa autobiográfica a partir dos encontros do autor com Amado Luiz Cervo², no escopo de constituição de uma família intelectual de Historiadores das RI.

O campo das RI embarcou tardiamente na jornada de integrar narrativas como parte da empreitada de entendimento científico e com uma linguagem clara. As abordagens autobiográficas e autoetnográficas continuam sendo incompreendidas nas RI "como uma maneira de conhecer o mundo", talvez porque tenham como ponto de partida o "eu" e suas singularidades,

\footnotetext{
2 Amado Luiz Cervo pode ser considerado figura emblemática em guiar uma "locomotiva de produção do conhecimento" e inspirador de importante "família intelectual", a da História das Relações Internacionais (HRI) de tradição brasileira. Uma comunidade conectada por suas pesquisas de iniciação científica, dissertações de mestrado, teses de doutorado, conformada de internacionalistas que se tornaram professores, pesquisadores, servidores públicos (gestores e diplomatas) e que transitaram entre os mundos das ideias e da prática. Amado Cervo foi meu professor na Universidade de Brasília nos cursos de graduação em Relações Internacionais (RI), mestrado em História e doutorado em RI. Participou nas minhas bancas de qualificação de mestrado e doutorado e na minha defesa de mestrado. Nos tornamos bons amigos.
} 
particularidades e peculiaridades nascentes no "mundo interior de uma mente que compartilha [suas] experiências" (INAYATULLAH, 2020).

$\mathrm{O}$ argumento central deste artigo é que ninguém é, mas se torna um Historiador das RI, o que significa dizer que se estabelece uma teia complexa de relações emocionais, psicológicas e institucionais que são responsáveis pela tessitura de múltiplas camadas de identificação e representação atreladas a um ofício (BLOCH, 2002). Procurei estabelecer um diálogo entre o foco em personagens históricos, a emergência da história global e o repensar a história para as relações internacionais, particularmente pela valorização da narrativa autobiográfica como instrumental epistemológico.

Como resultado, criei um enquadramento (framing) ancorado em torno de três categorias analíticas: vivências, intersubjetividades e intertextualidades. Acessei uma miríade de fontes históricas para a consecução desta empreitada intelectual, desde memórias pessoais e da época de aluno na UnB (vivências), lembranças da convivência como colega, colaborador e frequentador do círculo pessoal de Amado Cervo (intersubjetividade), bem como pela apreciação das ideias e crenças contidas em sua obra (intertextualidade).

Organizei o artigo em cinco partes principais. $\mathrm{Na}$ primeira, discuto a ideia de que o Historiador de RI é um internacionalista, olhando para a influência de Amado Cervo e sua obra na constituição de uma família intelectual; na segunda, mergulho em algumas vivências que construíram o meu caminho como internacionalista em contato com a História; na terceira, pondero sobre alguns elementos marcantes para o ofício de Historiador das RI; na quarta parte comento sobre as origens do projeto "espírito das Relações internacionais"; e concluo com algumas palavras finais sobre a empreitada de se tornar um Historiador das RI.

\section{O Historiador é um internacionalista ${ }^{3}$}

Como um tipo ideal (WEBER, 2001) de Historiador das RI, Amado Luiz Cervo pode ser entendido, decifrado e questionado como um "tipo

\footnotetext{
${ }^{3}$ Por internacionalista podemos conceber aquele/a que construiu sua carreira e formação na ciência política e relações internacionais estudando e pesquisando temas da política internacional ou aquele/a proveniente de outras áreas do conhecimento e que aprecia temáticas diversas (saúde, pobreza, urbanização) olhando para as dinâmicas e conexões com o internacional (regional, mundial e global).
} 
ideal"4, um internacionalista que enfrentou resistências originadas no império cognitivo da politologia ocidentalista (SANTOS, 2019). Em sua trajetória, fortaleceu o sentido que que o historiador como internacionalista se legitima ao voltar-se aos elementos identitários das RI, totalmente atrelados à História (GEHRE \& ARRAES, 2013).

De fato, o Historiador das RI precisa desenvolver habilidades comuns e diferenciadas de outros internacionalistas, mas que, sem dúvida, perfazem um processo de constante aprendizagem: das noções básicas de escrita (que estabeleça um diálogo entre explicação científica e narrativa literária) (GADDIS, 2003); do pensar os regimes de temporalidade e as conexões entre passado-presente-futuro (HARTOG, 2017); da escolha e delimitação dos objetos de estudo, seus significados e representatividades pessoais e profissionais; das habilidades com o uso do ferramental analítico, alguns deles ligados ao uso de métodos qualitativos e quantitativos (REUS-SMIT \& SNIDAL, 2008); instrumentalização de teorias, conceitos, e de uma infinidade de técnicas de pesquisa (KNUTSEN \& MOSES, 2012). Particularmente o mergulho nos arquivos talvez seja uma das vivências mais desafiadoras e formadoras de um Historiador das RI. A paciência da coleta, seleção, leitura, separação, categorização e organização das fontes primárias. Da releitura, mineração de informações valiosas à tessitura de um texto coerente, uma narrativa (TRACHTENBERG, 2006).

O ofício de Historiador das RI se define, ademais, pela capacidade de interlocução com uma literatura de múltiplas áreas. A intertextualidade é eixo estruturante do modo pelo qual é possível compreender uma das trajetórias possíveis para tornar-se um internacionalista. Por um lado, as intertextualidades se referem à construção de um conhecimento na área da História das RI que se vale de leituras e releituras da massa de conhecimento produzida desde o século 19 - particularmente sobre História - e com maior força e clareza a partir dos anos 1940 sobre História e Relações Internacionais. Os entendimentos extraídos dos textos produzidos por Amado Luiz Cervo ao

\footnotetext{
4 Pensar mediante o conceito de "tipo ideal" gera inteligibilidade nesta simbiose entre racionalidade e subjetividade, entre realismo e utopia na produção de um "conceito históricoconcreto".
} 
longo de sua vida acadêmica são fontes legítimas e seguras para suscitar reflexões sobre passado, presente e futuro.

Por um lado, Cervo abriu o caminho para a construção de uma obra duradoura sobre a História da Política Externa Brasileira, agregando às diferentes edições de seu manual, entre 1992 e $2020^{5}$, novas reflexões sobre o passado e as continuidades em sua narrativa sobre a história do presente. Por outro, abriu uma trilha para se discutir os "desafios internacionais" (CERVO, 1994) e, com especial atenção à América Latina e ao Cone Sul (CERVO; RAPOPORT, 1998; CERVO, 2001) desde uma perspectiva histórica. Ao mesmo tempo, estabeleceu pelo menos dois eixos essenciais da tradição brasileira de estudos internacionais: 1) estudos sobre relações bilaterais (CERVO, 1992), que evoluíram para o estudo das parcerias estratégicas (LESSA, 2013); 2) o foco nos conceitos, mais do que nas teorias internacionais, especialmente na construção de conceitos a partir de uma perspectiva histórica (CERVO, 2008).

Outra dimensão do internacionalista historiador advém das intersubjetividades, dos encontros e desencontros entre pessoas e seus objetos de estudo, assim como a maneira que encontramos para lidar com os desafios pessoais e profissionais que cruzam nossas trajetórias. Encontrei Amado Cervo muitas vezes ao longo de minha vida, o que moldou minha conexão com esta família intelectual e me desafiou a me tornar um historiador das RI que pudesse ter uma marca própria em termos de estilo de escrita, inclinações ideológicas, visão de mundo e inspirações.

Encontros e desencontros me tornaram o Historiador de RI que sou. Para aquelas gerações que se interessem em ter na História a plataforma de lançamento para suas empreitadas científicas e acadêmicas, é válido compreender o tamanho da obra que esta família intelectual já produziu no Brasil. Neste contexto, Cervo seria responsável por estimular uma certa "reciprocidade" no processo de associação das pessoas em torno de um sistema de crenças (ideias) (MARTINS, 2002), fortalecendo a consciência de pertencimento à área da História das RI no Brasil e na América Latina (PAUGAM, 2017).

\footnotetext{
${ }^{5}$ Vale menção que no prelo da Editora da UnB a nova edição da obra História da Política Exterior do Brasil, 2020.
} 


\section{Vivências na História das Relações Internacionais no Brasil}

Desde o ingresso na universidade como graduando do curso de Relações Internacionais na Universidade de Brasilia e durante toda minha formação, como mestrando e doutorando, e já como professor de uma Universidade pública no norte do Brasil pairava aquela dúvida existencial: como seria de fato meu futuro profissional?

Minhas vivências junto à História das RI foram decisivas em encontrar uma resposta a esta questão. A partir de 1997, ainda como calouro do curso de $\mathrm{RI}$ na $\mathrm{UnB}$, timidamente fomos eu e alguns colegas de grupo procurar material de referência ${ }^{6}$ para um trabalho da disciplina de Introdução ao Estudo das Relações Internacionais (IERI), do então jovem professor Danilo VonSperling, que exigiu bastante trabalho de pesquisa. Encontramos, então, na figura de Amado Cervo a primeira acolhida, quando nos emprestou material sobre a história de grupos terroristas, objeto de nosso seminário naquele semestre. $^{7}$ Nos anos seguintes, criei dois elos acadêmicos de proximidade com o grupo de Historiadores de RI: o interesse por América Latina ${ }^{8}$ e ao seguir os passos de José Flávio Sombra Saraiva (então pupilo de Amado Cervo), primeiro como aluno e monitor na disciplina de História das Relações Internacionais Contemporâneas (HRIC), e logo como tutor de pesquisa no Instituto Brasileiro de Relações Internacionais (IBRI). Em seguida J. F. S. Saraiva se tornaria meu orientador de dissertação de mestrado. ${ }^{9}$

\footnotetext{
${ }^{6}$ Naquela época o uso do computador e da internet como ferramentas de pesquisa ainda eram bastante limitados, o que nos deixava como alternativa a busca física/presencial no catálogo da BCE e a solicitação de livros e material dos nossos professores.

${ }^{7}$ Alguns de meus colegas de curso passaram a seguir mais de perto a trajetória daquele grupo de professores do Departamento de História (Amado Cervo, Estevão Rezende Martins, J.F. S. Saraiva, Wolfgang Döpcke, Albene Miriam Meneses, Norma Breda dos Santos) que viriam a contribuir com a criação do primeiro curso de Doutorado em RI no Brasil, no IREL da UnB.

${ }^{8}$ Vale o registro que meus pais Maely Santos Costa Gehre e Homero Filgueiras Galvão, que foram alunos da UnB nos anos 1960, influenciaram esta inclinação especial pela América Latina ao me proporcionar a vivência em casa, das histórias contadas e da cultura (cinema, música e literatura) latino-americana.

${ }^{9}$ Com importante influência de J F S Saraiva, curiosamente minha dissertação de mestrado, defendida em $1^{\circ}$ de julho de 2003 , e transformada em livro logo depois, seria um dos primeiros esforços intelectuais de entendimento da América do Sul como conceito da política externa brasileira, abrindo uma avenida para outros estudos como "A América do Sul no Discurso Diplomático Brasileiro" (Funag, 2005), de Luís Cláudio Villafañe G. Santos, e "O Horizonte Regional do Brasil", de Leandro Freitas Couto (Juruá, 2009).
} 
Desta trajetória recordo vivamente que todas as terças e quintas, a partir das 14h, assistíamos às aulas de Amado Cervo sobre a HPEB. Em um tom monotônico, intercalado por uma piada que poucos entendiam, e sempre atento àquelas folhas amareladas que retirava de sua pasta estilo 007: "eram os originais do seu livro", sussurravam na sala, ao se referirem a sua obra de referência com Clodoaldo Bueno (CERVO; BUENO, 2008).

Amado Cervo seria capaz de capturar "the sense of sea change", como diria Lynn Hunt (2014), fazendo evoluir o ensino da História para as RI, da cadeira de História Diplomática nos anos 1980, da HPEB nos anos 1990, a HRIB nos 2000 e nos últimos anos já considerando que o que estava ensinando seria uma História da Inserção Internacional/Global do Brasil (GALVAO ; MROS, 2017).

As escolhas de disciplinas optativas, a redação de minha monografia de final de curso, bem como minha pesquisa e colaboração no IBRI iriam definir meu relacionamento com vários colegas professores e pesquisadores. Todos eles estiveram presentes em momentos significativos da minha transformação em um historiador das RI, na figura de orientadores, em mesas de discussão, bancas de qualificação e defesa, como colegas de trabalho e em parceria em publicações. ${ }^{10}$

Um texto simples sobre a integração regional e o relacionamento entre Brasil, Argentina e Venezuela tornou-se uma dissertação de mestrado sobre a Política Externa Brasileira no tempo longo, das suas origens no século 19 à Reunião de Presidentes de Brasília de 2000. A América do Sul marchou comigo e continuou como referência em minha tese de doutorado - o primeiro estudo sistematizado e de esforço de compreensão histórica das relações bilaterais Brasil e Venezuela. As convivências de uma experiência completa de quatro anos de pesquisas, leituras, análises e interpretações - que refletiam o crescimento do campo de estudo da história das relações internacionais no Brasil (SARAIVA ; CERVO, 2005) - impactariam na minha transformação como Historiador das RI.

\footnotetext{
${ }^{10}$ Compilo destacadamente meus encontros com alguns dos principais personagens de minhas vivências como Historiador de RI: Estevão Martins, Albene Maria, Antônio Carlos Lessa, Virgílio Arraes, Carlos Vidigal e Pio Penna Filho, além de colegas latino-americanos, como Raul Bernal-Meza e Alejandro Mendible.
} 


\section{Tornar-se Historiador de RI ${ }^{11}$}

As vivências dentro e fora do campo acadêmico subsidiaram na construção das minhas habilidades gerenciais, cognitivas e psicossociais como um internacionalista. Por isso não podemos dizer que alguém simplesmente "é algo". Quando se vive em sociedade, você "se torna algo", justamente pelos encontros e desencontros, pelo acumulado de episódios e contatos estabelecidos na sua trajetória pessoal e profissional.

Da minha graduação ao mestrado foi o caminho de formação inicial: dominar as ideias, conceitos e o ferramental metodológico de Historiador das RI. Na defesa de minha dissertação, Cervo chamaria atenção sobre a relevância de se ter um argumento sólido e consistente quando se trabalha com o chamado "tempo longo" (BRAUDEL, 2005). O risco era perder o "fio da meada" e não conseguir produzir uma narrativa elegante. A transposição de minha dissertação em um livro (GEHRE, 2009 foi fruto de um trabalho de síntese e reorganização de ideias, especialmente de categorização e conceituação, que se tornou marca registrada da História das RI no Brasil e em Brasília (CERVO, 2008).

Do mestrado ao doutoramento foi o momento de amadurecimento. Intercalado com o exercício da docência - desde julho de 2001 - o espaço de experiência da tese é marcado pelas diferentes formas de contato com o orientador: alguns mais próximos - praticamente guiando seus orientandos consoante suas agendas e interesses de pesquisa - outros mais distantes ou dando mais liberdade para que os orientandos realizem seu trabalho em seu tempo e velocidade. A banca de qualificação torna-se o ponto médio nesta trajetória. Amado Cervo foi contundente: "aonde estão as fontes primárias, aonde está a empiria?" Seriam elementos que respaldariam a densidade e o ineditismo do meu trabalho doutoral como "um esforço intelectual marcante".

Tornar-se Historiador de RI é uma imersão na complexidade do mundo: de encontros intergeracionais que suscitam continuidades e

\footnotetext{
11 O tema central do artigo é inspirado no livro de Rene Girault "Etre historien de RI" que conheci pela primeira vez como aluno de graduação, fitando curiosamente a estante de livros de Amado Cervo em sua sala no Departamento de História, no ICC, Campus Darcy Ribeiro da UnB. A obra de Girault se debruçava evidentemente sobre a França e, em uma perspectiva eurocêntrica, procurava pontuar o que seria um Historiador de RI. Desde aquele dia permaneceu em mim esta grande inquietação de como seria escrever texto similar pensando a realidade brasileira e de um Historiador das RI no Brasil. GIRAULT, René. Être historien des relations internacionales. Université de Paris I - Sorbonne, 1998.
} 
descontinuidades; dos diálogos, conexões, amizades e rivalidades entre todos aqueles e aquelas que de alguma forma fizeram e fazem parte da sua vida pessoal e profissional; de adensamento de um laborioso trabalho de construção de um campo do conhecimento muito particular para a realidade brasileira; da construção de valores e virtudes especiais para este ofício. Nada obstante, é possível sistematizar algumas das características definidoras de um Historiador das RI em seu papel social. ${ }^{12}$

Viver o internacional tem relação direta com o Ensinar História para as Relações Internacionais. Umas destas dimensões é sem dúvida o acesso ao internacional por meio de filmes, livros, arte em geral, pesquisa de campo e viagens de trabalho e culturais. Portanto, um historiador de RI deve estar antenado à nova produção de conhecimento da área. $\mathrm{O}$ advento da sociedade da informação iria facilitar este acesso a novas obras e pesquisas (publicadas em revistas científicas internacionais). Mas permanece valiosa a prática de garimpar livros em viagens internacionais. Apontava Cervo, "Acabei de chegar de Paris, de onde trouxe 5 livros para saber o que eles estão pensando e produzindo em relações internacionais". ${ }^{13}$ Cervo sabia da importância de um internacionalista se apresentar na "vida internacional". Contara a ele sobre minha recente jornada como pesquisador visitante na Suécia, na Universidade de Lund. Ele replicou: "gostei de saber que está nesse país, Suécia, onde estive em seminários internacionais. Você está no caminho certo: professor de Relações internacionais deve viajar. ${ }^{14}$

Delinear um mapa de ações é um artifício importante para o historiador de RI executar seu trabalho. Cervo acumulara durante anos de carreira uma visão sobre grandes projetos (editoriais ou desenho de pesquisas), o que lhe permitia enxergar lacunas na produção do conhecimento e atalhos às dificuldades institucionais e burocráticas para a concretização de propostas e ideias. ${ }^{15}$ O caminho para Cervo seria "primeiro definir o escopo do projeto" e,

\footnotetext{
12 Nesta parte da narrativa, com autorização de Amado Cervo, fiz uso de e-mails trocados no período recente de 2015 a 2020, como uma forma de capturar alguns elementos importantes que constituem esta ideia de "se tornar um historiador de RI".

${ }^{13}$ E-mail, Cervo para Gehre. qui. 8 de jun. de 2017. 9:26.

${ }^{14}$ E-mail, Cervo para Gehre. sex. 21 de fev. de 2020. 8:56.

15 Cervo ponderou sobre dois projetos que eu lhe apresentei: um livro sobre as RI na Amazônia" e a criação de um centro de pesquisa denominado Global Politics, Historical International Relations. Por um lado, saudou as possibilidades do livro, por seu potencial; por
} 
consoante sua vasta experiência como pesquisador, pensar em termos de "bolsas de produtividade no $\mathrm{CNPq}$, para fins de criar uma rede de debates acadêmicos". A relevância e força de uma empreitada como a criação de um Centro de Pesquisa especializado demandaria a liderança de um acadêmico com perfil de coordenador para assumir as seguintes funções: “a) definir o projeto de modo concreto, com o tema de cada pesquisador, que iria elaborar o projeto-aspecto de sua responsabilidade; b) convidar os colaboradores para integrar o grupo, com todo o cuidado; c) encaminhar o conjunto dos projetos, porém de forma individualizada, semelhante a antiga modalidade de projeto integrado; d) acionar tarefas operacionais de apoio logístico ao desempenho do grupo: seminários, artigos prévios, debates em rede etc.”

Ver o mundo por lentes críticas respalda a seriedade do labor de um Historiador de RI, que deve trabalhar com diferentes perspectivas embasadas na empiria. Em episódio recente, Cervo reagiu à entrevista de Steven Levistsky sobre o governo Bolsonaro. ${ }^{16}$ Não escapa ao olhar crítico e atento de Cervo análises superficiais e historicamente descontextualizadas. Cervo opunha-se a qualquer interpretação "idiota de um americano ignorante, que não sabe nada sobre o Brasil e sobre nosso sistema político. Mas que gosta de ganhar dinheiro com leitores também ignorantes, americanalhados". ${ }^{17}$

Amado Cervo construiu uma obra entremeada por narrativas criticando os compromissos internacionais assumidos por governos sem qualquer preocupação com os interesses nacionais, dos tratados desiguais assinados durante o Brasil Império aos mais recentes acordos de livre comércio com norte-americanos e europeus; destacou os projetos abortados de industrialização e a própria industrialização tardia e dependente do capital estrangeiro; condenou as tentativas de espoliação dos bens públicos e das riquezas naturais do país, da abertura à navegação do Amazonas no século 19 à instalação de um modelo de Estado Normal ideologicamente associado ao neoliberalismo (CERVO; BUENO, 2008); assim como - em total alinhamento à objetividade do ofício de historiador que marcou sua geração e formação -

outro foi realista quanto ao centro de estudos: "Creio que este projeto não está maduro: genérico e ainda pouco operacional”. E-mail, Cervo para Gehre. Seg. 21 de set. de 2015. 9:55.

${ }^{16}$ LEVISTSKY, Steven. Como as Democracias Morrem. RJ: Zahar. Entrevista Disponível em: https://www.nexojornal.com.br/entrevista/2019/08/28/O-estado-da-democracia-nogoverno-Bolsonaro-segundo-este-autor?utm campaign $=$ sds\&utm source $=$ Newsletter

${ }^{17}$ E-mail, Cervo para Irelstaff. dom. 1 de set. de 2019. 9:55. 
registrou o declínio da política externa no período do Partido dos Trabalhadores no poder (CERVO; LESSA, 2014).

Capturar os tempos (suas diferentes representações) e decifrar seus mistérios é o motivador do historiador das RI. O tempo em si apresenta-se como aliado do Historiador de RI, em seu objetivo de "tornar-se". Amado Cervo construiu uma obra ao longo dos vários anos de sua carreira sendo que "seu legado nas Ciências Humanas no Brasil" transcendeu os campos da História e das RI ao versar sobre múltiplas temáticas ontológicas, metodológicas e epistemológicas. Tão importante como reagir de maneira quase que instantânea às demandas, urgências e emergências que muitas vezes pautam a vida dos cientistas sociais, é preciso construir um entendimento mais profundo sobre a complexidade da vida internacional. O seu acumulado de conhecimento, refletido em seus livros, artigos, teses e dissertações orientadas, intervenções em bancas e seminários, confluíam para a vasta seleção de fontes arquivísticas coletadas e de obras que fizeram parte da sua biblioteca, cuidadosamente edificadas ao longo do tempo, "sem pressa"! ${ }^{18}$

Preservar as memórias, pessoais e institucionais, é uma das tarefaschave de um Historiador das RI (LE GOFF, 2001). Além dos arquivos é possível acessar informações pelo uso da História Oral (entrevistas e depoimentos), resgatando traços que vivifiquem personagens marcantes em seus contextos. A preservação das memórias relaciona-se ao legado a ser deixado para gerações futuras. As teses e dissertações orientadas por Cervo seriam sem dúvida "um bom acervo de pesquisa" e a possibilidade de que gerações futuras pudessem fazer este "exercício de revisitar sua obra." 19

Em 8 de julho de 2019 Amado Cervo já estava empacotando todo aquele material, "cerca de 200 [teses e dissertações] "em cujas bancas participei no Brasil e no exterior, desde os anos 1970". Quando cheguei ao "Quintas da Alvorada", residência de Cervo, 26 pacotes de textos impressos me esperavam. Começamos a colocar no meu carro para levá-los a uma sala do IREL-UnB. Cervo sabia se tratar de "um material precioso e original sobre relações internacionais, que o pesquisador pode consultar, citar e aproveitar em suas

\footnotetext{
${ }^{18}$ E-mail, Gehre para Cervo. ter. 5 de fev. de 2019. 11:18.

19 E-mail, Cervo para Gehre. qua. 4 de jul. de 2019. 8:30. E-mail, Gehre para Cervo. qua. 3 de jul. de 2019. 12:44
} 
publicações". ${ }^{20}$ Além disso, estava bastante contente em doar sua coleção de livros à Universidade Federal de Santa Maria (UFSM) "que vai colocar minha biblioteca em uma sala própria e exclusiva, com uma placa de entrada: Ao Filho de Santos Anjos - Amado Luiz Cervo, biblioteca particular". ${ }^{21}$

Pensar o futuro é cada vez mais uma das principais elaborações para um Historiador das RI. Segundo Margareth Macmillan (2010, p.9) "melhor compreende o que está por vir, o tempo futuro, aquele que entende bem o passado". Em um dos últimos e-mails trocados com Amado Cervo, onde ele contava como estava convivendo com esta "praga" (Covid-19) e o isolamento e distanciamento sociais necessários nesta situação. ${ }^{22}$ As grandes epidemias criam contextos de crise que nos remetem não apenas ao passado como nos fazem reimaginar o futuro, justamente para não deixar que os fardos cotidianos bloqueiem os esforços "to build for the future" (PACKARD, 2016).

Mas como as universidades públicas brasileiras poderiam responder, não apenas na área das Hard Sciences, mas também das Humanidades à crise do COVID-19? Cervo foi coordenador do Laboratório do Futuro na $\mathrm{UnB}^{23}$ o que me "parece um capítulo bastante interessante da sua carreira" e bastante pertinente para o momento que estamos vivendo. Explicava a Cervo que se a UnB tivesse uma instância pensando o futuro da Universidade, certamente estaria mais bem preparada para enfrentar crises como esta do COVID-19.

${ }^{20}$ A UFSM não poderia receber teses e trabalhos orientados por Cervo "porque não pode registrar em seu acervo, uma vez que os direitos autorais e outros registros não estão definidos ainda”. E-mail, Cervo para Gehre. sab. 20 de abr. de 2019. 10:09. E-mail, Cervo para Gehre. qua. 9 de jul. de 2019. 9:53.

${ }^{21}$ Um dos idealizadores e articuladores da realocação da biblioteca pessoal de Cervo de sua casa na Quintas da Alvorada, Brasília, para a UFSM foi "nosso amigo de Santa MARIA", professor Günther Mros que lembrara que Cervo havia nascido em Santos Anjos, perto de Vale Vêneto, no município de Silveira Martins. "O novo Campus da UFSM fica na encosta da montanha, depois da qual está Santos Anjos no vale”. Este aspecto animou Cervo a doar sua coleção de livros. E-mail, Cervo para Gehre. seg. 18 de jun. de 2018. 10:06; E-mail, Cervo para Gehre. qua. 6 de fev. de 2019. 9:53.

22 Diria Cervo: "Que bom que você está de volta. Logo que acabar essa praga vamos nos ver, saborear um Whisky e conversar. Por enquanto só uso esse mail. Aqui estamos bem. Eu, Cacá e o gato. Dou minhas caminhadas todos os dias, mas só falo com caminhantes de longe. Estou com saudade. Forte abraço. Amado".

${ }^{23}$ Laboratório de Estudos do Futuro (LEF) foi pensado por Cervo como uma plataforma de pesquisa avançada usando a metodologia da prospectiva para enfrentar alguns grandes desafios ou questões a partir de tendências históricas para traçar possibilidades de evolução no tempo futuro: "o que vai acontecer com o futuro das águas, florestas, cidades, população". O LEF fora desenhado aproveitando o capital humano e a diversidade de expertise dos pesquisadores e professores da UnB. Entretanto, o projeto original de Cervo seria dobrado aos desígnios políticos do reitor da ocasião, professor Lauro Mohry. 
Havia necessidade e possibilidade de uma resposta não apenas sobre o tempo presente, mas como pensar a partir do passado e olhando para o futuro. ${ }^{24}$

\section{O espírito das Relações internacionais}

"Agora quero descansar e me preparar para o céu, com muita cerveja, é claro." (E-mail, Cervo para Gehre. ter. 5 de fev. de 2019. 11:05)

Cervo queixava-se não da idade, mas talvez das limitações que foram se impondo à sua rotina bastante sistemática de trabalho. ${ }^{25}$ Mas restava fôlego para um último empreendimento, um livro para o qual ele me convidara a contribuir: venha "conversar sobre nosso Espirito". Explicara a Cervo meus interesses neste projeto. "primeiro porque é uma honra poder escrever ele com vc. Segundo porque gostaria de poder carregar a herança do seu pensamento para as próximas gerações participando diretamente deste processo". ${ }^{27}$ Cervo avançava aos poucos tentando resistir ao tempo e continuar empreendendo. "O Espírito das Relações Internacionais" seria um manual, a princípio, de “como pesquisar e escrever". No planejamento original, a primeira parte seria um diálogo com as teorias internacionais. Mas Cervo mudou os planos: "Desenvolvi um pouco mais a primeira parte, que ficaria sob sua responsabilidade, já que você molha a barba nas teorias. Fi-lo apenas com o fim de indicar meu modo de ver sobre as linhas de fundo do argumento, que deve ser inovador".

De fato, Cervo mostrara-se impaciente com o ritmo que tomara a produção do livro, demorando longos dois anos da sua estruturação inicial até a escrita. Precisava, na verdade, de um parceiro mais altivo que pudesse impulsionar seu trabalho. Em certo ponto desabafou: "quero informar que o Espírito das Relações Internacionais anda muito devagar" e “o capítulo que

\footnotetext{
${ }^{24}$ E-mail, Gehre para Cervo. qui. 20 de fev. de 2020. 12:06. E-mail, Gehre para Cervo. qua. 15 de abr. de 2020. 16:42

${ }^{25}$ Amado tem o costume de logo cedo subir para seu escritório, de onde despachava seus emails, fazia suas leituras e escrevia seus manuscritos. Bem como mantinha religiosamente os momentos de distração, da feijoada aos sábados no Gilberto Salomão, aos almoços e jantares festivos com seu grupo mais próximo de amigos.

${ }^{26}$ E-mail, Cervo para Gehre. qui. 8 de jun. de 2017. 9:26. E-mail, Cervo para Gehre. ter. 5 de fev. de 2019. 11:05

${ }^{27}$ E-mail, Gehre para Cervo. qua. 7 de jun. de 2017. 15:58.
} 
havíamos pensado para você, sobre as teorias, será outra coisa, não uma exposição das teorias". Concluiu: "Por isso, Thiago, acho melhor você esquecer esse projeto e tocar os seus próprios, que são bons e muitos, como poucos colegas nossos trabalham". Cervo fez do Espírito das RI sua maneira de resistir e empreender de maneira criativa e inovadora, assim como de resistir ao tempo. Explicava o novo sentido dado ao livro: "andei pensando e escrevendo alguma coisa a mais. Especialmente reformulei todo o esquema. De fato, será um livro bem diferente. Apenas exponho meu pensamento sobre... não descrevo, nem arrolo conclusões alheias". ${ }^{28}$

\section{Palavras finais}

Este texto, uma narrativa política que conecta teorias, conceitos, história e o pessoal, ganha vida nos aniversários de Amado Cervo (80 anos) e de Brasília (60 anos). Ambos continuam sendo icônicos para as leituras cruzadas de História e Relações Internacionais: Cervo por inspirar gerações no espírito internacionalista e Brasília por albergar as principais instituições de relações internacionais do país: o Ministério das Relações Exteriores e o Instituto Rio Branco, as embaixadas e legações diplomáticas e o Instituto de Relações Internacionais da UnB.

As vivências com Amado Cervo e o grupo da História das RI, bem como o fato de eu ter vivido em Brasília e levado Brasília comigo em todas as viagens de trabalho e minhas missões acadêmicas, de Boa Vista (Roraima) a Lund (Suécia), foi algo particularmente decisivo em minha trajetória. Ao me tornar Historiador de RI entendi que seguimos nos trilhos das gerações que nos antecederam, que moldamos nossa identidade e significação nos encontros e reconhecimento como parte de uma família de pesquisadores e intelectuais, cujas trajetórias convergem em vivências. Mas aprendi que precisamos ser autênticos e buscar mudanças de foco e atualizações tão necessárias aos estudos, pesquisas e ensino da História para as RI no século 21.

Como um rio, o Historiador de RI vai recebendo e cedendo partículas de ideias, valores, virtudes e experiências daqueles/as que cruzam nossos caminhos. As vivências são parte muito importante da formação do

28 E-mail, Cervo para Gehre. qua. 7 de jun. de 2017. 15:10. O "Espírito das Relações Internacionais" já se encontra no prelo e deverá ser publicado em breve pela Editora da UnB. 
Historiador de RI por levarem ao crescimento pessoal, amadurecimento intelectual e compreensão de nossa pequenez neste imenso universo. As vivências pessoais, institucionais, acadêmicas e culturais desembocaram em experiências adquiridas e trocadas ao longo da formação nos diferentes níveis, da graduação, mestrado e doutorado, responsáveis por moldar minha visão de mundo, mas especialmente minha destreza em usar as ferramentas a disposição para realizar pesquisa, escrever e ensinar sobre a HRI. Logo, me tornei Historiador das RI.

\section{Referências}

BLOCH, M. Apologia da História: ou o ofício do historiador. Rio de Janeiro: Jorge Zahar Editor, 2002.

BRAUDEL, F. Escritos sobre a história. São Paulo: Perspectiva, 2005.

CERVO, Amado Luiz. 1992. As relações históricas entre o Brasil e a Itália: o papel da diplomacia. Brasília: Editora Universidade de Brasília.

, A. L., org. O Desafio internacional. Brasília: EDUNB, 1994.

. \& RAPOPORT, M., orgs. História do Cone Sul. RJ. Revan, 1998.

CERVO, A. L. "Os grandes eixos conceituais da política exterior do Brasil". RBPI, ano 41, Número Especial, 1998, pp. 66-84.

- Relações Internacionais da América Latina: velhos e novos paradigmas. Brasília: IBRI, 2001.

\& BUENO, C. História da Política Exterior do Brasil. $3^{\mathrm{a}}$ Ed, Brasília: Editora UnB, 2008.

Saraiva, 2008.

Inserção internacional: formação dos conceitos brasileiros. São Paulo:

; LESSA, A. C. 2014. O Declínio: Inserção Internacional Do Brasil (2011-2014). RBPI 57 (2): 133-151.

GADDIS, J. L. Paisagens da História: como os historiadores mapeiam o passado. Rio de Janeiro: Campus, 2003.

GALVÃO, T. G.; MROS, G. A genealogia do ensino da História para as Relações Internacionais. Meridiano 47, 18: e18014, 2017.

GEHRE, T. América do Sul: a ideia brasileira em marcha. Curitiba: Juruá, 2009.

GEHRE, T.; ARRAES, V. Introdução ao estudo das relações internacionais. São Paulo: Saraiva, 2013. 
GILBERT, A. N. International Relations, and the Relevance of History. International Studies Quarterly, Vol. 12, No. 4 (Dec., 1968), pp. 351-359.

HARTOG, F. Crer em História. São Paulo: Autêntica, 2017.

HUNT, L. Writing History in the Global Era. NY/London: WW Norton \&Company, 2014 (Kindle Edition).

INAYATULLAH, N. Opinion - Internal Simultaneity: A Science of Autobiography. May 4 2020. Disponível em: https://www.eir.info/2020/05/04/opinion-internal-simultaneity-a-science-of-autobiography. Acessado: 21/05/2020.

LE GOFF, J. (org.). A História Nova. São Paulo: Martins Fontes, 2001.

LESSA, A. C. Parcerias Estratégicas do Brasil. Volume 1. Belo Horizonte: Fino Traço, 2013.

MACMILLAN, M. Usos e Abusos da História. Editora Record, 2010. People, personalities, and the past. London: profile Books, 2016.

MARTINS, E. C. de R. Relações Internacionais: cultura e poder. Brasília, IBRI, 2002.

MOSES, J. W; KNUTSEN, T. L. Ways of Knowing: competing methodologies in Social and Political Research. London: Palgrave Macmillan. $2^{\text {nd }}$ Edition, 2012.

PACKARD, R. M. A History of Global Health: Interventions into the Lives of Other Peoples. Baltimore: JHU Press, 2016.

PAUGAM, S. Durkheim e o vínculo aos grupos: uma teoria social inacabada Sociologias vol.19 no.44. Porto Alegre, Jan./Abr. 2017.

REUS-SMIT, C.; SNIDAL, D. The Oxford handbook of international relations. Oxford University Press, 2008.

SANTOS, B. de S. O fim do império cognitivo: A afirmação das epistemologias do Sul. Belo Horizonte: Autêntica, 2019.

SARAIVA, J. F. S; CERVO, Amado Luiz. O crescimento das Relações Internacionais no Brasil. Brasília: IBRI, 2005.

TRACHTENBERG, M. The Craft of International History: A Guide to Method. Princeton, NJ: Princeton University Press, 2006

WEBER, M. Ensaios de sociologia. Rio de Janeiro: Zahar Editores, 1979. 